\title{
INFANCIAS, FAKE NEWS Y (DES) DEMOCRATIZACIÓN EN AMÉRICA LATINA: ¿CÓMO ESTABLECER OTROS COMIENZOS A TRAVÉS DE LA EDUCACIÓN?
}

CHILDHOODS, FAKE NEWS AND (DE) DEMOCRATIZATION IN LATIN AMERICA: HOW TO ESTABLISH OTHER BEGINNINGS THROUGH EDUCATION?

Heloísa Andreia de Matos Lins $^{1}{ }^{\text {- Janaina Cabello }}{ }^{2}$ - José Orlando Ferreira de Miranda Júnior ${ }^{3}$

Fecha de recepción: 31-03-2021

Fecha de aceptación y versión final: 07-06-2021

\section{Resumen}

Este ensayo se centra en la importancia del derecho humano fundamental de los niños (también) a la información-participación (incluidas las especificidades de los niños sordos), en un momento de eclipse democrático y epistemológico como fenómeno global, pero con desarrollos particulares en América Latina y Brasil, en particular, en términos de (re) producción de desigualdades, violencia y también represión temática y lingüística, en el caso brasileño. Propone una reflexión en torno a los artificios de la llamada Posverdad - a través del fenómeno de las fake news/mentiras como formas oscurantistas y/o fascistas de poder discursivo y político - como mecanismo estratégico para difuminar las fronteras entre lo real y lo forjado, con impactos ya en políticas públicas y prácticas pedagógicas en Educación Infantil. Se busca recuperar la importancia central de la educación en derechos humanos desde la infancia, la participación activa y la ciudadanía para la configuración de nuevos inicios democratizadores. En este contexto, a partir de un breve mapeo (con aporte deleuzo-guattariano y en el pensamiento decolonial) sobre algunos hechos del escenario brasileño - reportados por vehículos periodísticos o analizados también en otros estudios - el trabajo teje algunas reflexiones sobre el escenario de las políticas públicas orientadas a la niñez y articula una discusión sobre temas interseccionales (también relacionados con el oyentismo y la sordera), para problematizar el adultocentrismo en estos cruces y en proyectos de gubernamentalidad antidemocrática. Finalmente, busca señalar algunas condiciones esenciales para el establecimiento de otros comienzos en la educación infantil.

Palabras clave: Derecho a la información - Educación para sordos - Educación en derechos humanos - Educación infantil.

\begin{abstract}
This essay focuses on the importance of children's fundamental human right to information and (also) participation (including the specificities of hearing-impaired children), at a time of democratic and epistemological eclipse as a global phenomenon, but with specific developments in Latin America and Brazil; in particular, in terms of (re) production of inequalities and violence as well as thematic and linguistic repression, in the Brazilian case. It proposes a reflection on the artifices of the so-called post-truth - through the phenomenon of fake news / lies as obscurantist and / or fascist forms of discursive and political power and as a strategic mechanism blurring the boundaries between the real and the forged, which already impacts on public policies and pedagogical practices in Early Childhood Education. It seeks to
\end{abstract}

\footnotetext{
${ }^{1}$ Prof. Dra. da Faculdade de Educação da UNICAMP. Brasil. Correo electrónico: hmlins@ unicamp.br ${ }^{2}$ Prof. Dra. da Universidade Federal de São Carlos (UFSCar). Brasil. Correo electrónico: janainacabello@ufscar.br

${ }^{3}$ Doutorando na Faculdade de Educação da UNICAMP. Professor da Universidade Federal do Pará UFPA. Brasil. Correo electrónico: jorlando@ufpa.br

Revista del Instituto de Investigaciones en Educación

ISSN 1853 - 1393

Resistencia, Chaco. Argentina
} 
recover the central importance of active participation, citizenship, and education in human rights since childhood, for the configuration of new democratizing beginnings. In this (post-truth) context, the work starts with a mapping (based on Deleuze-Guattarian and decolonial thought contributions) of some events in the Brazilian scenario - reported by journalistic means or analyzed in other studies. The essay then weaves some reflections on the scenario of public policies oriented to children and articulates a discussion on intersectional issues (also related to audism and deafness), in order to problematize adultcentrism in these crossings and in antidemocratic governmentality projects. Finally, it seeks to point out some essential conditions for the establishment of other beginnings in childhood education.

Key words: Right to information - Deaf education - Human rights education - Early childhood education. 
Los grupos y los individuos contienen micro fascismos siempre esperando la cristalización. [...]

Lo bueno y lo malo son solo el producto de una selección activa y temporal para reiniciar (Deleuze y Guattari, 1995, p. 6)

\section{Educación en América Latina y Brasil: entre las trampas del ultraliberalismo, el ultra conservadurismo y los fascismos}

Para iniciar nuestras reflexiones sobre los derechos de la niñez y la juventud, especialmente sobre los derechos a la participación activa y la ciudadanía, aquí con énfasis en el acceso a la información / comunicación, con respecto a la educación infantil (de niños oyentes y sordos), contextualizamos nuestro análisis basados en los ataques desdemocratizadores a los que el Sur global (en el sentido de Santos y Meneses, 2010; Galeano, 2010), en este caso, América Latina, así como el Brasil (donde proponemos enfocar las reflexiones), han sido, repetidamente, un objetivo colonial. Nuestra propuesta no es retomar varios estudios en esta dirección, ya que podemos encontrar importantes aportes teóricos, desde el giro decolonial, como en Quijano, Mignolo, Walsh, Freire, Santos, por ejemplo (Balestrin, 2013), pero atentarnos a esa articulación intrínseca macro y micro política, para centrarnos en la infancia y los procesos educativos relacionados, en este "rincón" del mundo. A partir de un breve mapeo de algunos hechos del escenario brasileño - reportados por vehículos periodísticos (con apoyo teórico y metodológico, en particular, Deleuze y Guattari, 1995) - y a partir del pensamiento decolonial, el trabajo teje algunas reflexiones sobre elementos de este territorio de las políticas públicas brasileñas y articula una discusión sobre temas interseccionales (también relacionados con el oyentismo y la sordera), para problematizar la relación entre adultos-niños en estos cruces y en diferentes proyectos de gubernamentalidad.

Así, uno de los aspectos centrales que pretendemos destacar es la necesidad de entender las amenazas actuales a las democracias latinoamericanas como un proyecto sistemáticamente reajustado, con nuevas formas (pero con la esencia colonial, ciertamente), muy bien sustentado y articulado por las fuerzas ultraliberales y ultraconservadoras de estos países mismos (en Brasil, también manifestado por los fascismos, como veremos más adelante), así como en la relación con las fuerzas del Norte global, obviamente. Teniendo en cuenta este contexto, entonces, buscamos lanzar reflexiones sobre los nuevos desafíos en la educación infantil (considerando también las infancias sordas).

En esta vía analítica, aún considerando el rencor o el odio a la democracia, como algo recurrente en los grupos dominantes, como enfatiza Rancière (2014), es decir, recordando que los sectores privilegiados de la sociedad nunca la aceptaron realmente, y mucho más allá de consideraciones necesarias sobre las debilidades y ambivalencias de la democracia representativa liberal, es importante estar atentos a las sutilezas del actual proyecto de poder con respecto a los ataques del fortalecimiento democrático efectivo en nuestra región (Levitsky y Ziblatt, 2018). En este sentido, así como Michael Löwy (2016) destaca: 
La democracia se interpone en el camino, no facilita el trabajo de la política capitalista. De ahí la tendencia a reducir el espacio democrático, a tomar medidas excepcionales e incluso a utilizar el método golpista, como estamos viendo en América Latina [énfasis agregado] (...) (Löwy, 2016, p. 962).

El proceso de investir por la fragilidad democrática, por lo tanto, comienza a tener contornos realineados, principalmente a partir del matrimonio reorganizado de los neoliberales con los conservadores. Varios estudios ya han destacado esta articulación desde un punto de vista histórico, pero actualmente observamos matices muy específicos en Brasil, con énfasis desde el gobierno de Bolsonaro y el fortalecimiento de sectores de poder fundamentalistas religiosos (Chauí, 2016; Almeida, 2019; Mariano, 2014, para citar algunos estudios), además del crecimiento de los escaños de gobierno regidos por la agroindustria, por la industria armamentística, como algunas de las fuerzas que ocupan un lugar preponderante en este territorio.

Aún, en el caso de Brasil, bajo el actual gobierno, además de la pretendida copia del trumpismo (también desde la lógica tradicionalista, como se comenta en el Autor 1, en prensa), hemos acompañado el fortalecimiento de (micro) fascismos (en una nueva gestación, más prominente desde las manifestaciones de 2013), como se mencionó inicialmente, considerando los aspectos subjetivos-colectivos y las peculiaridades brasileñas de mantener privilegios y hegemonías en términos interseccionales de clase/ raza-etnia y género/sexualidad, especialmente. Aquí consideramos una sociedad fundada y desarrollada sobre bases autoritarias, ciertamente, como señala Schwarcz (2019), repitiendo "el destino" lanzado estratégicamente a América Latina, por el mercado financiero internacional y también por nuestras élites. Ese aspecto ("la violencia de origen y su repetición") también está resaltado por Eduardo Galeano (2010), en la obra potente que se mantiene actual, debido a los problemas allí reflejados.

Podríamos, así, mencionar estos y otros aspectos que se han aglutinado como constitutivos del bolsonarismo (como lo entienden Freixo \& Pinheiro-Machado, 2019; Gomes, 2020; Gallego, 2018; Sena-Júnior, 2019; Souza \& Valim, 2018, por ejemplo) y aquí resumido por Sabrina Fernandes (2019):

El bolsonarismo surge como un fenómeno de estas creencias [que los comunistas están dividiendo al país] y surge como una fuerza autoritaria que tiene, entre ellos el objetivo de criminalizar tanto los movimientos sociales como la discusión del comunismo, asumiendo por terrorismo (Fernandes, 2019, p. 267).

Esto se debe a que, en resumen, vemos crecer una circulación de afectos en torno a la creación de enemigos, expresión directa del fenómeno de la ultra política, es decir, de un núcleo fascista en esta política, en la que el líder es visto como un "guerrero o general de guerra" (Zizek, citado por Fernandes, 2021, p. 268) y donde se crean estratégicamente falsas polarizaciones / falsas equivalencias (lo que por cierto ha seducido incluso a los principales medios brasileños como una "explicación" de fenómenos mucho más complejos). Tal política (rediseñada y consumida como apolítica o antipolítica, como señalan Francisquini, 2019 y Germani, 2017) se convierte en una "arena de violencia". Existe, por tanto, un proyecto de poder para el establecimiento del miedo-odio-ignorancia frente a lo que se ha pactado como un "enemigo común", es decir, las políticas de género, ambientalismo, movimientos sociales, prácticas antirracistas, etc., fácilmente traducido al público sediento de 
"justicia y moral", como formas satánicas / del "mal cósmico" (es decir, del "comunismo" o del "izquierdismo", de los "adoctrinadores" en el campo de la educación, por ejemplo), y dejar de ser un espacio de debate y disenso propio del juego democrático (ver Filgueiras, 2021; Zaffaroni, 2020, entre otros análisis).

Fernandes también señala que la ultra política "ofrece al líder fascista numerosas ventajas: desde demonizar a su oponente como un enemigo mítico hasta la atribución de superpoderes al líder, que aparecen como suficientes, haciendo innecesario el debate del proyecto" (Fernandes, 2019, p. 269), es decir, el establecimiento de una especie de vale todo, bajo el manto / disfraz que incluye la "democracia", los "derechos humanos" o el "funcionamiento normal" de las instituciones, cómo aún insiste en la repercusión los grandes medios de comunicación en Brasil.

Gino Germani (2017) conceptualiza tales amenazas a la democracia como "regímenes desmovilizantes". Como se argumenta en el Autor 1 (en prensa), esta estrategia de gubernamentalidad (en el sentido deleuzo-guattariano) - como trama que impide la existencia de posibles más allá del proyecto neoliberal / ultraconservador / moralista y reaccionario - impone la borradura o expulsión de la dimensión política (precisamente borrando el "buen" debate y los hechos concretos). Uno de los principales aliados de este bloque de poder son precisamente las fake news, como forma de incrementar el desconocimiento y la violencia (y también de su discurso o dimensión simbólica), como mecanismo político, como también lo comenta Mello (2020) - que aquí podríamos llamar neocolonial, neo-oscurantista, el "nuevo irracionalismo brasileño", o el lastre "brasileño" de alt right, la derecha alternativa, por ejemplo (al respecto, ver Autor 1, en prensa), como veremos más adelante.

En este contexto, en la situación política y social en la que se encuentra el Brasil y gran parte del mundo, se observan elementos de la llamada Pos verdad, término utilizado con más énfasis a partir de 2016, cuando la Oxford Dictionaries eligió pos verdad como la palabra del año en el idioma inglés. También conocida como el arte de manipular multitudes, la post-mentira, la pos censura, como lo llama Álex Grijelmo (2017), en un reciente artículo del diario El País. Al ofrecer soluciones engañosamente simples para situaciones honestamente complejas, la nueva ola de posverdad utiliza la insinuación, la suposición y la implicación, la falta de contexto y la inversión de relevancia, por ejemplo, para propagar mensajes falsos o "las nuevas verdades". En este sentido, la traductora periodística Bérengère Vienott (2020) llama la atención sobre la extrema simplificación de estos discursos como una forma muy efectiva de incitar a la violencia, como en el caso de sus análisis de las narrativas de Trump (y ciertamente lo hacemos extensivo a los discursos bolsonaristas). Es decir, estamos ante la era de las imposturas, en detrimento de la ciencia, el buen periodismo y la ética, más concretamente. O aún, nos enfrentamos al consumo accesible de los discursos simplistas de los nuevos populistas / autócratas en el poder (aparentemente "habladores", como señalan Levitsky \& Ziblatt, 2018, o como "una mezcla de payasos militares y de circo", según Safatle, 2018), para abordar cuestiones complejas.

De todos modos, como ahora todo es comprobable, conviene recordar que mentir no es tan sencillo, como también nos recuerda Grijelmo (2017). Por tanto, según el autor, este obstáculo (¡el hecho / realidad!) tiende a superarse con dos elementos centrales: la insistencia en el falso argumento, a pesar de las negaciones fehacientes, además de la descalificación de quienes discrepan y se oponen. Esto acaba funcionando como consecuencia de un tercer factor: millones de personas empezaron a prescindir de los "intermediarios de garantía", como los medios 
tradicionales, mucho en función del descrédito que se les imputa, claro (para no entrar en la discusión sobre su propia parte de responsabilidad en ese conjunto).

En este escenario, las tecnologías permiten actualmente la manipulación digital de cualquier documento (incluidas las imágenes), como se conoce. Por lo tanto, la evidencia "concreta" ya no tiene valor real. Tierra fértil (plana) para fake news, movimientos anti vacunas, creacionistas, negacionistas, revisionistas y todo tipo de absurdos al gusto también de las epistemologías "medievales".

Es importante considerar, según el periodista británico Matthew D'Ancona, The Guardian, que la pos verdad solo puede prosperar en un entorno en el que la indignación de la gente - frente a la corrupción, la deshonestidad y la falsedad de los políticos - cede paso a la indiferencia y, posteriormente, la connivencia (D’Ancona, 2018), que sin duda impone nuevos desafíos, tanto para los movimientos sociales, para las investigaciones y el campo de la educación.

En este sentido, el avance de una verdadera "cruzada moral" (Balieiro, 2018) del actual gobierno brasileño en materia de Derechos Humanos - como, por ejemplo, con la revisión de las políticas de Derechos Humanos en el país, el desmantelamiento del Consejo Nacional de derechos del niño y del adolescente (Conanda) y la regulación de la educación familiar, entre otros hechos recientes, sólo es posible frente a cierta indiferencia y connivencia de grupos privilegiados. Esto ha venido sucediendo, a través de la simplificación de discursos, narrativas "alternativas" y la profundización de binarismos falsificados, mientras debilita los derechos a la información y participación. Así, tal proyecto establece una fórmula: para desinformar y construir realidades paralelas, es necesario, al mismo tiempo, combatir y negar información concreta, desde la pequeña infancia.

Como una de las principales consecuencias de este comportamiento que se propaga y engendra mentalidades y subjetividades, incluso considerando los factores interseccionales de clase, raza / etnia, género y generación, los hechos "alternativos" están devorando la realidad misma. En este sentido, el Estado de derecho democrático se retrae y las llamadas culturas de paz se están convirtiendo en utopías inalcanzables.

En tiempos de oscurantismo, cuando es necesario defender lo obvio, cuando las fake news prevalecen sobre la ciencia, en muchos casos observamos, al mismo tiempo, que debido a las facilidades tecnológicas, se han imaginado las posibilidades de superponerse al empoderamiento de las llamadas minorías (sociológico, político, lingüístico, por ejemplo ...). Lo que, sin duda, convive en estos ciber territorios (Ferreira, 2018). Sin embargo, lo que hemos observado es el avance de la desinformación, en un mar de fake news (Barbosa, 2019). Cabe señalar que la "superconectividad" de Brasil ha hecho el crecimiento exponencial de tales mentiras, también en el caso de la educación, por ejemplo, más inicialmente a través del proyecto ultraconservador llamado Escola sem Partido, oficialmente extinguido, pero con impactos muy actuales en (in) acciones didácticas (Penna, 2018).

Ante esta constelación de elementos de corrosión democrática, en el caso brasileño, Nacif y Filho (2019), por ejemplo, destacan el papel fundamental de la educación, ya que: 
... es en el territorio de las políticas educativas que las lógicas oscurantista y de reducción del Estado se encuentran, de manera más radical, apuntando a una probable implosión de las conquistas de la sociedad brasileña en el período posconstitucional de 1988 (Nacif y Filho, pp. 236237).

En este sentido, en los primeros años del gobierno de Bolsonaro, podríamos mencionar aquí varias políticas educativas "desmovilizadoras" o "desmovilizantes", además de la Escola sem Partido (citado arriba), por utilizar el concepto de Germani (2017) mencionado, pero que fueron abundantemente reportados por los medios como el conocido caso del "kit gay" y la "ideología de género", como amenazas concretas a los intentos de fortalecimiento democrático, desde el entonces gobierno de la presidenta Dilma Rousseff, más notorias desde 2011.

En el ejemplo citado, las mentiras difundidas sobre lo que en realidad se configuró como "un conjunto de materiales que tenían el objetivo de combatir la homofobia en las escuelas brasileñas" (Maranhão, et. al, 2018, p. 69) giraron en torno a la defensa de la "familia tradicional brasileña" (y de sus hijos, por lo tanto), y causaron innumerables consecuencias en las políticas públicas brasileñas y las prácticas pedagógicas, ya que fueron / son difundidas por el discurso político / religioso como un "intento de sexualizar a los niños y hacer de la 'homosexualismo' una normalidad práctica”. (Maranhão et.al, 2018, p. 72)

Lo que nos gustaría enfatizar aquí, a partir de estos hechos cotidianos, es la esencia moralizante de estas políticas, dado el fundamentalismo religioso inicialmente señalado, como modus operandi de este Estado no secular (de hecho), de su estrategia neurálgica de gubernamentalidad, desde la educación de la infancia (ver más detalles en Autor 1, 2019) o, más explícitamente, por lo que se extirpa en términos políticos, es decir, también de su potencia para la garantía de participación/ ciudadanía de los niños. En esta dirección, Aviz y Girardello (2021), aunque tratan de una dimensión muy específica sobre los fundamentalismos religiosos y los impactos en la educación infantil (considerando que aquí nos referimos más a una dimensión simbólica en términos de violencia de Estado, ligada a un aspecto fundamentalista cristiano, en el caso brasileño actual), en una publicación reciente muestran cómo algunas corrientes religiosas - bajo las más variadas formas de manipulación - se enfocan precisamente en los niños "desde que gatean", como señalan las autoras, para inducirlos "[...] a sistemas de creencias. Las estrategias utilizadas para adoctrinar a estos niños indican la profundidad del miedo y la ansiedad que desarrollarán y cuán estrechamente están interconectados estos dos aspectos" (Aviz y Girardello, 2021, p. 1045). Además de este aspecto, recuperando las consideraciones de Marlene Winell (citado por Aviz y Girardello, 2021) - sobre lo que ella llama abuso de poder y abuso espiritual sobre los niños - las autoras enfatizan la táctica más poderosa del fundamentalismo cristiano extremista: el terror y cuánto "el miedo puede paralizar las fuerzas imaginativas" (p. 1045). También recuerdan que: "El fundamentalismo cristiano enseña la existencia del infierno: un lugar de tormentos eternos". (Aviz y Girardello, 2021, p. 1045)

Es en este contexto de fundamentalismo religioso o mesianismo (uno de los tipos asumidos por el "conservadurismo", aunque no sea el único), ligado al ultraliberalismo - ambos relacionados con el uso / disparo de fake news (Fernandes, 2019; Mello, 2020; Teitelbaum, 2020), sea por la urgencia de crear pánico / miedo moral al otro "enemigo" y / o por intereses económicos / de clase (donde pueden buscar o fortalecer las fuerzas del fascismo ) - que, a continuación, destacamos cómo 
la negación (aunque sea tácita) del derecho de los niños a la información / comunicación, o la censura, se convierte en una pieza central del engranaje "desmovilizante" de la ciudadanía activa y del fortalecimiento democrático más amplio, como consecuencia (es decir, de las capacidades subjetivas/ inventivas/ culturales y políticos de estos niños) - considerando la acepción de Eduardo S. Bustelo (2007) que diferencia la ciudadanía asistida de la ciudadanía emancipada.

Dicha desmovilización (subjetiva y colectiva) también ocurre, como señalan Aviz y Girardello (2021), a través de

... métodos y materiales que se utilizan en el adoctrinamiento de los niños desde la primera infancia con el fin de enfatizar el dualismo de la salvación y perdición e introyectar en la mente de los niños no solo el adoctrinamiento religioso, sino el horror del otro [énfasis agregado (Aviz y Girardello, 2021, p. 1047).

Métodos y materiales que anhelan la formación del "niño soldado", es decir, "el ejército de Dios" o miembros de una "milicia de los redimidos", según resumen, con base en el testimonio de una de las mujeres que fueron abusadas espiritualmente en la infancia y que participó en el estudio.

Un ejemplo emblemático de estas fuerzas ocurrió cuando, por ejemplo, la ministra-pastora (del actual Ministerio de la Mujer, Familia y Derechos Humanos, MMFDH), Damares Alves, declaró "caza de brujas" a los libros infantiles con temas de "seres mágicos, como brujas, hadas y duendes" (Oliveira, 2020), demonizando públicamente, a través de las redes sociales, tales temas, bajo una lógica muy específica de "formación" de los niños (moral/ religiosa/ cristiana). Uno de los impactos más directos fue la autocensura de gran parte del mercado literario infantil, como también apunta Oliveira (2020).

Aún como estrategia para evitar el acceso a la información (de ciertos temas considerados por el ala religiosa / conservadora / moralista como tabúes o inapropiados, como también se comenta en Lins, 2019; Lins, en prensa), más recientemente, destacamos la designación de Sandra Ramos, profesora ultraconservadora/ religiosa afiliada al Movimiento Escola Sem Partido y defensora del creacionismo, como coordinadora de materiales didácticos en el Ministerio de Educación. Además de esta nominación, hubo importantes supresiones en los últimos avisos del programa nacional de distribución de libros (didácticos y literarios), como la mención específica a la violencia contra la mujer y excluye la palabra 'democrática' de los principios éticos.

Desde nuestro punto de vista, dado este contexto analítico y atentos a las políticas públicas para la infancia, además de la reanudación de algunos hechos más emblemáticos, viendo un ejemplo en la imagen de abajo, hay un desprecio deliberado por la laicidad del Estado brasileño y por los derechos de la niñez en esta estela (aunque el discurso de la protección se promociona como una estrategia), que se configura como un intento teocrático en el país, como se comenta en el Autor 1 (en prensa). Como también argumentaremos en la secuencia, en este contexto, el papel de la educación infantil puede tener impactos importantes en alguna invención contra hegemónica, cuyas bases deben basarse en pedagogías decoloniales. 


\section{Figura 1}

Posteo en red social hecha por Damares Alves, la Ministra-pastora.

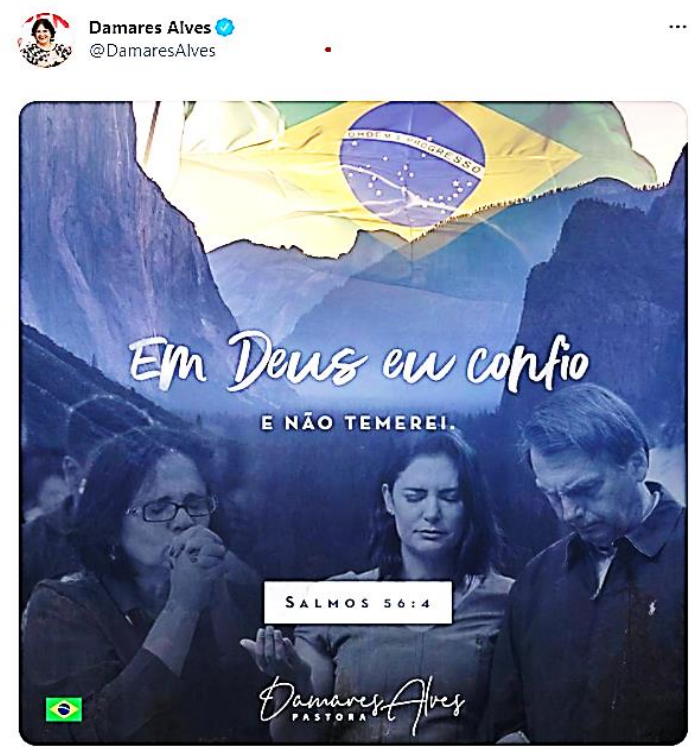

11:05 PM - 28 de mar de 2021 - Twitter for Android

Fuente: Twitter. https://twitter.com/DamaresAlves/status/1376354711461330944

\section{Sobre los derechos de información y comunicación de los niños y la democracia: educación infantil (des) amordazada en Brasil}

En el campo de los Estudios de la Infancia, existen importantes reflexiones sobre las debilidades, en la práctica, en cuanto a los derechos de participación de los niños, finalmente suscritos por la Convención sobre los Derechos del Niño, CDC (Unicef, 1989), con los casi 200 países signatarios, entre ellos el Brasil. De manera amplia y recurrente, existen subterfugios creados no solo desde un punto de vista centrado en el adulto, sino como configuraciones de políticas públicas regresivas o incluso autocráticas en varios países, que han hecho que la implementación de la denominada Doctrina de Protección Integral y el interés superior del niño se volviese impracticable, es decir, debilitan la inseparabilidad entre los derechos de protección, provisión y participación de la niñez y la juventud (Sarmento \& Tomás, 2020; Marchi \& Sarmento, 2017; Gaitán Muñoz, 2018; Thomas, 2009; Moss, 2009; 2019; Bae, 2016, entre otros estudios).

Como recuerdan Sarmento y Tomás (2020, p. 23): "La CDC impulsó una nueva concepción de la infancia y, reconociendo la capacidad de los niños para ser titulares de derechos, inauguró también una nueva categoría de derechos, los de participación, que confluyen provisión y protección [...] (Fernandes, 2009)”. De todos modos, los autores enfatizan que fueron las tensiones que se mantuvieron, cuando se consideran "el respeto, la garantía y el ejercicio de los derechos del niño" (Sarmento \& Tomás, 2020, p. 24). Aún considerando este escenario de dificultades concretas, Inês Barbosa (2020) señala que, actualmente, programas de la Comisión Europea, ONU y Unicef, por ejemplo, hacen explícitas sus intenciones en cuanto al derecho a la ciudadanía/ participación, desde la infancia (Barbosa, 2020). En este sentido, 
comúnmente se insiste en una posición de ciudadanía "abstracta" regida por prácticas políticamente correctas que se confunden con civismo/ civilidad: "vamos a formar el 'pequeño ciudadano de buen comportamiento'", como también lo señala Barbosa (2020). Dicho esto, cabe destacar que, como la autora, nos referimos aquí a la necesidad de una participación ciudadana activa, es decir, el ejercicio de una "ciudadanía crítica e inconforme" (ídem). Práctica, por regla general e incómoda para las referencias centradas en los adultos, al menos.

Así, en lo que respecta a los derechos humanos del niño, tal como se expresa en la Convención sobre los Derechos del Niño (Unicef, 1989) - más específicamente en el Art. 31, "a participar libremente en la vida cultural y en las artes", así como en el Art. 12 con una indicación del potencial de los niños frente a la información y sus expresiones, el Art. 13 acerca de la libertad de expresión, por ejemplo - nosotros enfatizamos un fuerte debilitamiento de los derechos de ciudadanía / participación activa de los niños, ya que encontramos evidentes rastros de censura y adoctrinamiento moral/ religioso (abajo mencionados, a partir de algunos programas gubernamentales). En el caso particular de las infancias, que ya están bastante alejadas de la participación activa también en nuestros países latinoamericanos - a diferencia de las democracias más consolidadas (como es el caso de Noruega y otros países nórdicos, por ejemplo, como lo analiza Bae, 2016) - y sistemáticamente excluidas de las más diversas situaciones sociales de influencia (Sarmento et. al., 2007), tales análisis son importantes, términos a la vista, como el derecho básico a la información de "calidad" (o sea, las que fortalecen preceptos progresistas y, efectivamente, democráticos) que sufre serias amenazas. En vista de lo anterior, cuando miramos también la educación de los niños sordos, consideramos que el escenario impone graves consecuencias pedagógicas y políticas. En este contexto, enfatizamos los orígenes históricos del movimiento socioeducativo de los sordos, en el que se observan los lazos religiosos entre los primeros "benefactores" hacia y desde los sordos. (Assis Silva, 2012)

Mello (2019) también llama la atención sobre lo que denominó "surdonacionalismo teocrático pentecostal", basado en las influencias religiosas históricas que se imponen a las comunidades sordas y, más recientemente, a la actuación de la Primera Dama del país, Michelle Bolsonaro, usuaria de la lengua de signos brasileña, como

... el surdonacionalismo teocrático pentecostal caritativo que ataca primero las políticas de discapacidad y luego se extiende a otros grupos sociales, con la excepción de la población LGBT, la única que ni siquiera está en el marco de la protección caritativa del nuevo gobierno que confunde la caridad con los "derechos humanos" (Melo, 2019, s / p).

Teniendo estas marcas históricas (¿amarras?), el momento actual que atraviesa la política brasileña y una supuesta acogida del gobierno bolsonarista a las "causas sordas" (Autor 2, 2021, p. 186), destacamos las amenazas también en torno al acceso a la información/ expresión de los niños sordos, ya que además de las borraduras y censuras antes mencionados (sobre los temas "tabú" relacionados con el fortalecimiento democrático, obviamente, porque involucran cuestiones interseccionales de clase, raza / etnia, género y sexualidad) a la que todos los niños están expuestos actualmente (aquí también consideramos el proyecto "Conta pra mim", del Ministerio de Educación, y los censores temáticos involucrados, como lo comenta Ramalhete, 2019), hay inversiones muy particulares en este grupo minoritario (doblemente, es decir, porque son sordos y niños). Significa que, desde nuestro punto 
de vista, tales aspectos del resurgimiento de los derechos del niño adquirirán contornos más nítidos cuando observamos la Política Nacional de Alfabetización, PNA (Brasil, 2019, que también impone importantes restricciones a la información de los niños oyentes, desde la perspectiva de la llamada alfabetización, cercana a la concepción reconocida como freireana, letramento, o sea "leer el mundo", como resume Ramalhete, 2019), reemplazado ahora por literacia, con el supuesto de lo que estratégicamente se denominó "método fónico visual", como una propuesta pedagógica para los niños sordos, y una especie de "retorno renovado" al discurso de la sordera como discapacidad - aparentemente superado, desde mediados de la década de 1980, en Brasil y en varios países, principalmente por las contribuciones de los estudios poscoloniales y las perspectivas antropológicas - en detrimento de la defensa de la sordera como diferencia, de hecho, como lo había sido la gran bandera de este grupo social en el período anterior.

Respecto a esta modalidad de censura en materiales/ bienes simbólicos y culturales destinados a la infancia, incluida la reanudación del momento de las dictaduras en América Latina, además de prácticas más actuales en este sentido, Belén Bouzas Gorgal (2017) destaca este artificio que acompaña a la propia historia de la escritura, así como indica que es un tema que aún no se ha estudiado en las academias.

Más allá de estos artificios en torno a temas considerados "inapropiados" en los libros de literatura infantil y palabras que ya no deberían formar parte de las políticas públicas (como "democracia", "violencia de género", alfabetización, como sinónimo de letramento o leer el mundo, como se señaló) - volvemos aquí a las palabras de Roig Rechou y Pousada Pardo (2016), en relación al análisis de las prácticas durante la dictadura gallega: un "sistema de censura fuerte (temática y lingüística)" que dejó huellas latentes de autocensura, diglosia y represión lingüística, hasta los días actuales - también destacamos la Política Nacional de Educación Especial (Brasil, 2020). Dicho programa fue propuesto por el gobierno federal brasileño y ya juzgado como inconstitucional por la Suprema Corte Federal (STF), considerando que tales políticas públicas "debilitan el imperativo de inclusión", pero aceptado por buena parte del movimiento de sordos, así como de muchos oyentes. Tal política pone en riesgo el ya precario acceso de los niños sordos a la educación bilingüe ( $y$ al letramento), de hecho, en la forma en que la analizamos, proponiendo el regreso a las escuelas y clases especiales y la flexibilidad de los sistemas educativos para (los llamados) "estudiantes con discapacidades", que refuerza viejos estereotipos (Autor 2, 2021).

No pretendemos aquí detallar los aspectos complejos allí involucrados, considerando que la población sorda no estaba siendo atendida satisfactoriamente por políticas públicas previas (tampoco educativas), como se puede profundizar en el Autor 2 (2021), pero lo que pretendemos aquí sacar a la luz son los cambios explícitos que percibimos en las principales agendas del movimiento social sordo, desde la actual influencia gubernamental (posiblemente por las matrices religiosas/ morales comunes, pero no solo, dada la complejidad del momento político que atraviesa el país, por ejemplo), y cómo estos elementos incidirán en la educación de los niños sordos, considerando el ámbito de participación / información / derechos de ciudadanía, a partir de ahí. Esto se debe a que, como ya hemos señalado, además de estar más "tuteladas" desde el punto de vista de la información, del centrado moralista adulto que "pasteuriza" o simplemente elimina los contenidos considerados inapropiados para la infancia - ahora como política de Estado - son nombrados/ reconocidos como "personas con discapacidades" - y antes de eso sería bastante 
controvertido para los grupos que abogan por una perspectiva educativa bilingüe/ bicultural y progresista. Todavía están bajo la influencia de otro aspecto de este oyentismo que estableció la noción de "normal x deficiente" (Skliar, 1998), tan exclusivo y amenazador para las especificidades culturales, lingüísticas y subjetivas de las personas sordas, precisamente porque producen y reproducen tácticas y estrategias de normalización para sordos, basadas en las referencias de los oyentes, como destaca Skliar (1998).

Ahora, a través del mencionado "método fónico visual", destacamos, no solo las pérdidas en cuanto a la lectura del mundo/ letramento de los niños (de todos, sordos y oyentes), sino la reanudación de las prácticas de enseñanza oral, históricamente combatidas, precisamente por infligir a las personas sordas el sufrimiento de ser vistos como marginales social y biológicamente, "una subespecie de la raza humana" (Sánchez, 1990, p. 52).

Además de esta lamentable situación, el reciente cierre de TV INES, una Web TV estatal abierta, vinculada al Instituto Nacional de Educación para Sordos (INES), la única emisora del país cuyo material fue transmitido íntegramente en Lengua de Señales brasileña, Libras, (con traducción en audio y subtítulos en portugués) y, como señalan Ribeiro, Cabello y Lins (2020), una de las tres emisoras del país que presentan contenido político en señales. Así, es evidente hasta qué punto su cierre se configura como una política que, al hacer imposible /inviable que las personas sordas tengan acceso a la información ( $y$, por supuesto, los niños/niñas sordos/as en este contexto), pone sus derechos de acceso a la información, participación en riesgo y el ejercicio de la ciudadanía de los sordos, aumentando su vulnerabilidad a las fake news y también la ya existente "brecha referida a un derecho humano fundamental que es la comunicación y el desempeño político de estos ciudadanos (considerando la estricta y también la ciudadanía global)" (Ribeiro, Cabello y Lins, 2020, pp. 325-326).

La TV INES ha sido un aliado importante en el proceso educativo de las personas sordas, considerando el derecho a la información / comunicación. Como se explicó anteriormente, sus actividades interrumpidas afectan el derecho constitucional, como nos recuerda Santos (1996/1997), al considerar "ciudadanías mutiladas". Es ante la falta de información oficial al contexto jurídico-político (que ahora se está volviendo aún más profundo para los sordos, ante semejante extinción), que reforzamos el entendimiento de que "la comunidad sorda ha construido" redes paralelas "para la producción y circulación de información, comunicación y participación política" (Ribeiro, Cabello y Lins, 2020, p. 328), reivindicando su participación en la construcción de una ciudadanía más plural y justa (también para niños y jóvenes).

Teniendo en cuenta también la complejidad y gravedad del momento actual de la "Edad Media al revés", en el que "no hay oscuridad como en el pasado medieval, sino un exceso de luz excesivamente inquietante" (Sayad, 2019, p. 71), es incluso paradójico que, si bien "las luces del conocimiento" están potencialmente distribuidas y disponibles, hay mucha desinformación causada, irónicamente, precisamente por esta abundancia y, en el caso de los niños (y particularmente los niños sordos), la situación se agrava cuando consideramos que, con el advenimiento de las tecnologías digitales, es posible que nunca hayan tenido tanto acceso a la información, a pesar de que están bajo la intensa tutela de adultos. Siguiendo el escenario sociopolítico brasileño más amplio, enfrentan importantes escollos en términos de garantizar los derechos de información y participación, que ahora están más sujetos a pedagogías que han sido arrastradas, en su mayoría, por líneas oscurantistas (Autor 2, 2021). Es decir, además 
de la escucha y las vulnerabilidades históricas que se generan en torno a sus derechos de formación subjetiva/ identitaria (considerando también que los sordos son parte de un grupo cultural y lingüístico específico), otros modos de colonialidad del poder-saber imponen dispositivos de control / gubernamentalidad (relacionado con la mismidad y no con las diferencias) en la educación de los niños sordos, como ya ocurre en el caso de los niños oyentes.

\section{Derechos humanos de los niños (también sordos) en tiempos oscuros: ¿qué puede hacer la educación?}

Con relación a los derechos de los niños a la información y la comunicación (oyentes y sordos), la accesibilidad a los bienes simbólicos y culturales, como se argumentó, también encontramos énfasis en el papel del aprendizaje fuera de las escuelas, más específicamente en lo que se refiere a la fuerza formativa de los medios de comunicación, entre otros vehículos (como libros de literatura infantil, dibujos animados, programas de televisión, así como la propia Internet, por ejemplo). Ribeiro, Cabello y Lins (2020) señalan que, en un documento reciente de Unicef (2017), se destacan importantes aspectos del papel de los medios, como televisores y radios, en el fortalecimiento de los derechos de información y comunicación para garantizar y hacer cumplir los derechos humanos (también de niños), con énfasis en los grupos más marginados y socialmente vulnerables. La propuesta del organismo multilateral, por tanto, se refiere a la inseparabilidad entre los contextos de desarrollo, acceso y humanitario.

Es importante destacar, en este sentido, que documentos más recientes sobre las demandas del movimiento social sordo, como el "derecho lingüístico en lengua de señas a la información que circula socialmente" (Febrapils, 2018, s/n) fueron discutidos en el estudio referido. A modo de síntesis, la investigación realizada ya señaló que la información fundamental para el ejercicio de la ciudadanía por parte de las personas sordas, principalmente por las noticias de la TV abierta brasileña, ha sido poco accesible (antes, por lo tanto, del cierre de TV INES, mencionado arriba).

En vista de esta importante brecha en el derecho a la información / comunicación y el potencial de participación ciudadana (ver Ribeiro, Cabello y Lins, 2020), tales debilidades que también surgen en términos de otras infancias (no en términos de traduccíon, necesariamente, sino en relación con los contenidos, como señalamos anteriormente), es fundamental reflexionar sobre cómo construir caminos para el establecimiento de la educación plural y democrática como táctica contra la hegemonía. De la misma manera, dadas las especificidades en el campo de los derechos del niño y la accesibilidad a la información / comunicación, es necesario cuestionar los supuestos también de la educación de los niños sordos que pueden ser (re) inventados y / o repetidos como un área epistemológica de la formación humana, como enfatizamos anteriormente.

Después de todo, al modo de una pedagogía freireana de la pregunta, reflexionamos ¿qué mundos y subjetividades ha proyectado o puede proyectar la educación infantil (considerando también a los niños sordos) en tiempos de pos verdad? Así, en general, ¿qué enfrentamientos ha visibilizado y asumido la educación infantil, ante las nuevas realidades y dispositivos de control / desdemocratización, reuniendo infancias que fueron separadas / categorizadas - también estratégicamente por el pensamiento moderno y la cientificidad - como "normales" o no? ¿Qué borrones, 
fronteras e insurgencias se nos podrían presentar en estos escenarios en los que el lenguaje / lenguaje también entrelaza realidades?

Por tanto, como buscamos reiterar, es fundamental que la educación en derechos humanos, basada en supuestos decoloniales (y no universalistas), como señalan Oliveira y Candau (2010) y Tavares (2020), se defienda y practique desde la educación infantil, considerando, en este contexto, la centralidad de la participación y ciudadanía activa de los niños (¡de todos(as/es), con la misma intensidad y estatus de importancia!) para la configuración de un nuevo horizonte democrático.

En el ámbito de la educación en derechos humanos, coincidimos con Saravali (2021) en que el proceso de aprendizaje "trasciende la legislación, las declaraciones y los documentos firmados" (p. 73), pero necesita una comprensión de sus derechos para poder reclamarlos. En el contexto político brasileño actual, Cássio (2019) enfatiza que "la educación debe ser desbarbarizada" (p. 16). Esta parece ser una forma poderosa de diseñar y construir nuevos comienzos para la educación infantil: no naturalizar tales oscurantismos, así como no ceder a categorizaciones nosológicas de la infancia (o cualquier otra marca interseccional que refuerce las desigualdades entre los niños/niñas, en lugar de buscar superarlos), y (re) ubicar la potencia de la participación infantil, de manera equitativa, en nuestras reflexiones y acciones políticopedagógicas.

Como nos recuerdan Aviz y Girardello (2021) sobre el adoctrinamiento de las infancias, bajo las prendas de "protección": "Es una máquina discursiva que intenta evitar que los niños construyan su propia historia, y así vivir una historia lista [... ] que encuentran "natural" tener horror del otro" (Aviz y Girardello, 2021, p. 1056). De igual forma, otras mentiras que circulan por internet y redes sociales son parte de estos poderosos modos de subjetivación infantil, del "paquete de materialidades" de (des) información que obviamente van en sentido contrario a los preceptos libertarios y democráticos.

Como hemos destacado, bajo las trampas del discurso moral / religioso de la protección y el cuidado, una vez más, las infancias (sordas y oyentes) están siendo privadas paulatinamente de una educación como ejercicio pleno de ciudadanía o, mejor dicho, de vivencia del derecho al protagonismo / participación activa en la construcción de una ciudadanía no regida por prejuicios, fantasías o fanatismos (que históricamente se sigue aún negando o debilitando). Una educación infantil comprometida con la libertad y la pluralidad de existencias, por tanto, no puede ignorar estos aspectos en su currículo y no permitir la censura previa de los bienes culturales destinados a los niños/ niñas.

En resumen, en la trayectoria reflexiva que aquí presentamos, buscamos recuperar la importancia central de la educación en derechos humanos ligada a pedagogías decoloniales que presten atención a los riesgos de los tradicionalismos / mesianismos religiosos y de la pos verdad, de los borrados estratégicos en bienes simbólicos destinados a la infancia - que son vulnerables en varios aspectos, pero especialmente en la dimensión política de la formación humana, desde las guarderías - contando con su participación fundamental y sus modos de expresión, para la configuración de nuevas formas antifascistas, anti-imperialistas, anti-sexistas, antiracistas, es decir, de nuevos comienzos en torno a la política de la amistad, de las diferencias ( $\mathrm{y}$ ya no del fortalecimiento de prácticas de persecución a lo que convencionalmente se concibe como "los enemigos"). Creemos que este establecimiento de mundos más justos y plurales necesita ser guiado, debatido y vivido de manera urgente, cotidianamente, en los proyectos político-pedagógicos de la 
Educación Infantil en nuestros países, asumido como un campo temático importante en la investigación académica en las universidades latinoamericanas, así como en otros entornos y por agentes formadores de nuestras sociedades, tan profundamente estructuradas por la violencia, la desigualdad y la negación de derechos a determinados colectivos, desde las invasiones bárbaras de la Modernidad.

\section{Referencias bibliográficas}

Almeida, R. (2019). Bolsonaro Presidente: conservadorismo, evangelismo e a crise brasileira. Novos estudos CEBRAP. Recuperado de http://www.scielo.br/scielo.php?script=sci_arttext\&pid=S0101$33002019000100010 \& \operatorname{lng}=$ en\&nrm=iso

Assis Silva, C. A. (2012). Cultura surda: agentes religiosos e a construção de uma identidade. São Paulo, Brasil: Terceiro Nome.

Aviz, R. L., Girardello, G. (2021). Fundamentalismos religiosos e pequena infância: reflexões que importam à educação. Revista Zero-a-Seis. Recuperado de https://periodicos.ufsc.br/index.php/zeroseis/article/view/74343

Bae, B. (2016). O direito das crianças a participar - desafios nas interações do quotidiano. CIED - da investigação às práticas. Recuperado de: https://ojs.eselx.ipl.pt/index.php/invep/article/view/107/157

Balestrin, L. (2013). América Latina e o giro decolonial. Revista Brasileira de Ciência Política, (n. 11), 89-117. doi: https://doi.org/10.1590/S010333522013000200004

Balieiro, F. F. (2018). "Não se meta com meus filhos": a construção do pânico moral da criança sob ameaça. Cadernos Pagu, (n. 53), 1-14. doi: https://doi.org/10.1590/18094449201800530006

Barbosa, I. (2020). Direitos cívicos e políticos na infância e adolescência: da retórica da participação ao protagonismo infantil. Sociologia: Revista da Faculdade de Letras da Universidade do Porto, pp. 69-89. doi: https://doi.org/10.21747/08723419/soctem2020a4

Barbosa, M. (2019). "Isso a imprensa não mostra". En Pós-verdade e fake news reflexões sobre a guerra de narrativas (pp. 7-23). Rio de Janeiro, Brasil: Cobogó.

Brasil (2020). Decreto no 10.502 de 30 de setembro de 2020. Institui a Política Nacional de Educação Especial: equitativa, inclusiva e com aprendizado ao longo da vida. Brasília: Ministério da Educação.

Brasil (2019). Decreto no 9765, de 11 de abril de 2019. Institui a Política Nacional de Alfabetização. Brasília: MEC. Recuperado de: <https://legis.senado.leg.br/norma/30902116/publicacao/30905492>

Bustelo, E. S. (2007). El recreo de la infancia: Argumentos para otro comienzo. Buenos Aires, Argentina: Siglo veintiuno editores.

Cabello, J. (2021). Cartografia das (re)territorializações no movimento social surdo no Brasil atual: (des)caminhos para as pedagogias surdas como devir. [Tesis de doctorado]. Universidade Estadual de Campinas, São Paulo, Brasil. http://www.repositorio.unicamp.br/handle/REPOSIP/359090 .

Cássio, F. (org.) (2019). Educação contra a barbárie. São Paulo, Brasil: Boitempo Editorial.

Chauí, M. (2016). A nova classe trabalhadora brasileira e a ascensão do conservadorismo. En: Jinkins, I., Doria, K, Cleto, M. (orgs). Por que gritamos 
golpe? Para entender o impeachment e a crise política no Brasil. São Paulo, Brasil: Boitempo.

D'ancona, M. (2018). Pós-verdade: a nova guerra contra os fatos em tempos de fake news. Tradução: Carlos Szlak. Barueri, Brasil: Faro Editorial.

Deleuze, G, Guattari, F. (1995). Mil Platôs. (Capitalismo e Esquizofrenia). São Paulo, Brasil: Editora 34.

Federação Brasileira das Associações dos profissionais tradutores e intérpretes e guia-intérpretes de língua de sinais. (2018). Direitos humanos das pessoas surdas: pela equidade social, cultural e linguística. Recuperado de: http://febrapils.org.br/direitos-humanos-das-pessoas-surdas-pela-equidadesocial-cultural-e-linguistica/.

Fernandes, S. (2019). Sintomas mórbidos: a encruzilhada da esquerda brasileira. São Paulo, Brasil: Autonomia Literária.

Ferreira, M. F. (2018). Infância (in)ativa: potencialidades de participação e cidadania às crianças na mídia digital. Tese de doutorado em Comunicação. Faculdade de Arquitetura, Artes e Comunicação, Universidade Estadual Paulista (UNESP). Recuperado de https://repositorio.unesp.br/handle/11449/157357

Francisquini, R. (09 de abril de 2019). Bolsonaro e a antipolítica. Le Monde Diplomatique Brasil. Recuperado de https://diplomatique.org.br/bolsonaro-e-aantipolitica/.

Filgueiras, L. (11 de marzo de 2021). Os principais aliados ativos do vírus: o ovo se transformou em serpente. Le Monde Diplomatique Brasil. Recuperado de: https://diplomatique.org.br/o-ovo-se-transformou-em-

serpente/\#: :text=E\%200\%20sistema\%20de\%20sa\%C3\%BAde,amea\%C3\% A7a\%20\%C3\%A0\%20sa\%C3\%BAde\%20p\%C3\%BAblica\%20mundial.

Freixo, A., Pinheiro-Machado, R. (2019). Dias de futuro (quase) esquecido: um país em transe, a democracia em colapso. En Pinheiro-Machado, R., Freixo, A. Brasil em transe: bolsonarismo, nova direita e desdemocratização (pp.9-24). Rio de Janeiro, Brasil: Oficina Raquel.

Galeano, E. (2010). As veias abertas da América latina. Tradução: Sérgio Faraco. São Paulo: L\&PM. Recuperado de: http://www.lpm.com.br/livros/lmagens/veiascon.pdf.

Gaitán Muñoz, L. (2018). Los derechos humanos de los niños: ciudadanía más allá de las "3Ps". Sociedad e Infancias, 2, 17-37. doi: https://doi.org/10.5209/SOCl.59491

Germani, G. (2017). Democracia y autoritarismo em la sociedad moderna. En: Calderón, F. (Org). Los límites de la democracia. Aníbal Quijano [et al.]. Buenos Aires, Argentina: CLACSO.

Gorgal, B.B. (2017). (Recensión) Prohibido leer. La censura en la literatura infantil y juvenil contemporánea. Elos. Revista de Literatura Infantil e Xuvenil / n. 04 / 2017 / pp. 129-132. Recuperado de: https://revistas.usc.gal/index.php/elos/article/view/4134

Grijelmo, A. (28 de agosto de 2017). A arte de manipular multidões: técnicas para mentir e controlar as opiniões se aperfeiçoaram na era da pós-verdade. El país. Recuperado de: https://brasil.elpais.com/brasil/2017/08/22/opinion/1503395946_889112.html.

Harari, Y. (2018). 21 lições para o século 21. São Paulo, Brasil: Companhia das Letras.

Klemperer, V. (2009). LTI: a linguagem do Terceiro Reich. Rio de Janeiro, Brasil: Contraponto.

Latour, B. (31 de marzo de 2019). O sentimento de perder o mundo, agora, é coletivo. El País. Recuperado de:https://brasil.elpais.com/brasil/2019/03/29/internacional/1553888812_6526 
80.html?ssm=IG_BR_CM\&utm_campaign=later-linkinbio-

elpaisbrasil\&utm_content=later-

15445565\&utm medium=social\&utm source=instagram.

Levitsky, S., Ziblatt, D. (2018). Como as democracias morrem. Rio de Janeiro, Brasil: Zahar.

Lins, H.A.M.(en prensa). "Bora proteger as crianças?" em tempos obscurantistas no Brasil: retóricas da inimizade como escudo à participação política. En Lins, H.A.M. (org.). Democracia e participação das infâncias e juventudes no Brasil: cidadanias mutiladas.

Löwy, M. (2016). Da tragédia à farsa: o golpe de 2016 no Brasil. In: Jinkings, I., e Doria, K., e Cleto, M. (Orgs). Por que gritamos golpe? Para entender o impeachment e a crise política no Brasil. São Paulo, Brasil: Boitempo.

Maranhão, E. M. A., Coelho, F. M. F. y Dias, T. B. (2018). "Fake news acima de tudo, fake news acima de todos": Bolsonaro e o "kit gay", "ideologia de gênero" e fim da "família tradicional". Revista Correlatio, n. 2, (2), 65-90. doi: https://doi.org/10.15603/1677-2644/correlatio.v17n2p65-90

Mariano, R. (2014). Neopentecostais: sociologia do novo pentecostalismo no Brasil. São Paulo, Brasil: Loyola.

Marchi, R. C, Sarmento, M. J. (2017). Infância, normatividade e direitos das crianças: transições contemporâneas. Educação e Sociedade, v. 38 (n. 141), 951-964. doi: https://doi.org/10.1590/es0101-73302017175137.

Mello, A. G. (04 de enero de 2019). A caridade de Michelle Bolsonaro e o surdonacionalismo pentecostal como projeto de governo. Catarinas. Recuperado de https://catarinas.info/a-caridade-de-michelle-bolsonaro-e-osurdonacionalismo-pentecostal-como-projeto-de-governo/.

Mello, P. C. (2020). A máquina de ódio. Notas de uma repórter sobre fake news e violência digital. São Paulo, Brasil: Companhia das Letras.

Moss, P. (2009). Introduzindo a política na creche: a Educação Infantil como prática democrática. Psicologia USP. 20(3), 417-436. doi: https://doi.org/10.1590/S0103-65642009000300007

Moss, P. (2019) Alternative Narratives in Early Childhood: na Introduction for Students and Practitioners. New York, EEUU: Routledge.

Nacif, P. G. S., y Filho, P. S. (2019). A educação brasileira na mira do obscurantismo e Estado mínimo. Brasil: incertezas e submissão? São Paulo: Fundação Perseu Abramo, 231-249. Recuperado de https://fpabramo.org.br/publicacoes/wpcontent/uploads/sites/5/2019/09/Brasil-incertezas-e-Submiss\%C3\%A3oEpub1.pdf. Acceso en 15/02/2021.

Oliveira, J. (13 de febrero de 2020). 'Caça às bruxas' de Damares provoca autocensura no mercado literário infantil. El País. https://brasil.elpais.com/cultura/2020-02-13/caca-as-bruxas-de-damaresprovoca-autocensura-no-mercado-literario-infantil.html.

Oliveira, L. F, Candau, V. M. (2010). Pedagogia decolonial e educação antirracista e intercultural no Brasil. Educação em Revista. 26(1), 15-40. doi: https://doi.org/10.1590/S0102-46982010000100002

Penna, F. (2018). O discurso reacionário de defesa de uma "escola sem partido". En Gallego, E. S. (org.). O Ódio Como Política: a reinvenção das direitas no Brasil. São Paulo, Brasil: Boitempo Editorial.

Ramalhete, M. P. (2020). O retrocesso empurra a porta: a literatura infantil e o programa Contra pra Mim. Revista do Centro de Letras e Comunicação. n. 38, 151-167. Recuperado de https://periodicos.ufpel.edu.br/ojs2/index.php/cadernodeletras/article/view/198 27

Rancière, J. (2014). O ódio à democracia. São Paulo, Brasil: Boitempo Editorial. 
Ribeiro, B., Cabello, J.y Lins, H.A.M. (2020). Direito à participação política da comunidade surda brasileira: informação e comunicação na garantia de cidadania. Humanidades \& Inovação. v. 7 n. 20: Direitos Humanos II. Recuperado de: https://revista.unitins.br/index.php/humanidadeseinovacao/article/view/3638.

Roig Rechou, B., Pardo, V. P. (2016). Censura y sus efectos en la LIJ galega. En Torremocha, P. C.C., Ortiz, C.S. (org.). Prohibido ler. La censura em la literatura infantil y juvenil contemporánea. Cuenca: Ediciones de la Universidad de Castilla-La Mancha, 2016, 452 p (Estudios; 158)

Safatle, V. (2018). O que é fascismo? TV Revista Cult. https://www.youtube.com/watch?v=_ypurfdlPmU

Sánchez, C. (1990). La increíble y triste historia de la sordera. Caracas, Venezuela: CEPROSORD.

Santos, B. de S., Meneses, M. P. (Orgs.) (2010). Epistemologias do Sul. São Paulo, Brasil: Editora Cortez.

Santos, M. (1996/1997). As Cidadanias Mutiladas. En Dines, A. et. al. O Preconceito. São Paulo, Brasil: IMESP.

Saravali, E. G. (2021). Dando voz à criança pequena sobre seus direitos. En: Almeida, N. B. (Org.) Os Direitos Humanos à Prova do Tempo: reflexões breves sobre o presente e o futuro da humanidade. Campinas: BCCL/UNICAMP. Recuperado de https://drive.google.com/file/d/1yGIOzrPjGSxaauPz4oYCY64IK4Tm9Ok/view

Sarmento, M. J., Fernandes, N., Tomás, C. (2007). Políticas públicas e participação infantil. Educação, Sociedade e Cultura, v. 25, pp. 183-206. Recuperado de http://repositorium.sdum.uminho.pt/handle/1822/36753

Sarmento, M. J.; Tomás, C. (2020). A infância é um direito? Sociologia: Revista da Faculdade de Letras da Universidade do Porto, Número Temático - Direitos das crianças: abordagens críticas a partir das ciências sociais, pp. 15-30. doi: https://doi.org/10.21747/08723419/soctem2020a1

Sayad, A. (2019). Idade Média: uma Idade Média às avessas. En Barbosa, M. (org.) Pós-verdade e fake news: reflexões sobre a guerra de narrativas (pp. 69-77). Cobogó.

Schwarcz, L. M. (2019). Sobre o autoritarismo brasileiro. São Paulo, Brasil: Companhia das Letras.

Sena Júnior, C. Z. (2020) Obscurantismo e anticientificismo no Brasil bolsonarista: anotações sobre a investida protofascista contra a inteligência e a ciência no Brasil. Cadernos do GPOSSHE On-Line, 3(1), 21-49. doi: https://doi.org/10.33241/cadernosdogposshe.v3i1.1987

Skliar, C. (1998). A surdez: um olhar sobre as diferenças. Porto Alegre, Brasil: Mediação.

Souza, J.; Valim, R. (2018). Resgatar o Brasil. São Paulo, Brasil: Contracorrente.

Tavares, C. (2020). Educação em Direitos Humanos na Educação Básica. Revista Olhares. 8(2), 1-2. Recuperado de: https://periodicos.unifesp.br/index.php/olhares/article/view/10710

Teitelbaum, B. R. (2020). Guerra pela eternidade: o retorno do Tradicionalismo e a ascensão da direita populista. Campinas, Brasil: Editora da Unicamp.

Thomas, N. (2009). Children, politics and communication: participation at the margins. Bristol, London: British Library.

Unicef. Fundo das nações Unidas para a infância. (1989). Convenção sobre os Direitos da Criança. Recuperado de: https://www.unicef.org/brazil/convencaosobre-os-direitos-da-crianca.

Unicef. Fundo das Nações Unidas para a Infância. (2017). Communication for Development (C4D): Global Progress and Country Level Highlights Across 
Programme Areas. Recuperado de: https://www.unicef.org/publications/index_102938.html.

Wyllys, J. (15 de dezembro de 2020). Fake news: a arte de enganar na política (e a de querer ser enganado por ela). Revista Fórum. Recuperado de: https://revistaforum.com.br/blogs/socialistamorena/fake-news-a-arte-deenganar-na-politica-e-a-de-querer-ser-enganado-por-ela/.

Zaffaroni, E. R. (16 de noviembre de 2020) Lawfare y democracia en América Latina. Curso Internacional Estado, Política y Democracia en América Latina. Recuperado de: https://americalatina.global/clase-5/

\section{Notas}

(1) Sobre la brutalización de todas y cada una de las relaciones sociales y el miedo como un afecto político esencial, características centrales del fascismo y la realidad brasileña, ver, por ejemplo, Vladimir Safatle en TV Revista Cult en: https://www.youtube.com/watch?v=_ypurfdIPmU. 22 de oct 2018. Acceso el $03 / 12 / 2021$

(2) Considerando que el fenómeno entre la mentira y la política / proyectos de poder está íntimamente ligado en la historia. Véase, por ejemplo, Harari (2018) y Latour (2019).

(3) Vienott (2020) también recuerda, inevitablemente, las similitudes de este tipo de discurso actual con el discurso nazi. En cuanto al uso de la repetición de mentiras para hacerlas verdaderas, consulte también el trabajo de Victor Kemplerer (2009) sobre el período nazifascista.

(4) Recuperado de: https://www.correiobraziliense.com.br/politica/2021/03/4909752-damaresdefende-revisao-da-politica-de-direitos-humanos-e-reage-as-criticas.html Acceso en 07.03.2021

(5) Recuperado http://portal.mec.gov.br/component/content/article?id=75061:educacaodomiciliar. Acceso en 07.03.2021.

(6) Consultar: https://www.escolasempartido.org . Acceso en 14.03.2021.

(7) Es importante considerar, sin embargo, que el fenómeno de la producción de mentiras en la política ha involucrado históricamente a espectros de derecha e izquierda (y más allá). Véase, por ejemplo, el breve análisis de Jean Wyllys, víctima y estudioso de las fake news, político y activista brasileño (Willys, 2020).

(8) Recuperado de: https://veja.abril.com.br/educacao/bolsonaro-marcha-firmepara-impor-agenda-ideologica-no-ensino/.

(9) Recuperado de: https://g1.globo.com/educacao/noticia/2021/02/17/edital-delivros-escolares-retira-mencao-especifica-a-violencia-contra-a-mulher-e-excluipalavra-democraticos-dos-principios-eticos.ghtml.

(10) Recuperado de http://alfabetizacao.mec.gov.br/30-conta-pra-mim.

(11) Detalles disponibles http://www.stf.jus.br/portal/cms/verNoticiaDetalhe.asp?idConteudo=457869

en: 